\title{
Trajectory of the main GABAergic interneuron populations from early development to old age in the rat primary auditory cortex
}

\section{Lydia Ouellet and Etienne de Villers-Sidani *}

Department of Neurology and Neurosurgery, Montreal Neurological Institute, Montreal, QC, Canada

\section{Edited by:}

Anderson Mon, All Nations

University College, Ghana

\section{Reviewed by:}

Deanna L. Benson, Mount Sinai

School of Medicine, USA

Paul A. Gray, Washington University,

USA

Jean-Pierre Hornung, University of

Lausanne, Switzerland

*Correspondence:

Etienne de Villers-Sidani, Department of Neurology and

Neurosurgery, Montreal

Neurological Institute, 3801 Rue

University, Montreal, QC H3A2B4,

Canada

e-mail: etienne.de-villers-sidani@ mcgill.ca
In both humans and rodents, decline in cognitive function is a hallmark of the aging process; the basis for this decrease has yet to be fully characterized. However, using aged rodent models, deficits in auditory processing have been associated with significant decreases in inhibitory signaling attributed to a loss of GABAergic interneurons. Not only are these interneurons crucial for pattern detection and other large-scale population dynamics, but they have also been linked to mechanisms mediating plasticity and learning, making them a prime candidate for study and modeling of modifications to cortical communication pathways in neurodegenerative diseases. Using the rat primary auditory cortex (A1) as a model, we probed the known markers of GABAergic interneurons with immunohistological methods, using antibodies against gamma aminobutyric acid (GABA), parvalbumin (PV), somatostatin (SOM), calretinin (CR), vasoactive intestinal peptide (VIP), choline acetyltransferase (ChAT), neuropeptide Y (NPY), and cholecystokinin (CCK) to document the changes observed in interneuron populations across the rat's lifespan. This analysis provided strong evidence that several but not all GABAergic neurons were affected by the aging process, showing most dramatic changes in expression of parvalbumin (PV) and somatostatin (SOM) expression. With this evidence, we show how understanding these trajectories of cell counts may be factored into a simple model to quantify changes in inhibitory signaling across the course of life, which may be applied as a framework for creating more advanced simulations of interneuronal implication in normal cerebral processing, normal aging, or pathological processes.

Keywords: aging, auditory, A1, inhibition, GABA, parvalbumin, somatostatin, interneurons

\section{INTRODUCTION}

The cerebral cortex is a complex computational machine, simultaneously processing environmental information through a delicate balance of excitation and inhibition. In the mammalian cortex, this is accomplished by two main neuron subpopulations: excitatory glutamatergic neurons, constituting about $80 \%$ of all cortical neurons, and inhibitory GABAergic interneurons, representing 20\% of the total neurons population (DeFelipe, 1993; Martinez et al., 2002; Markram et al., 2004; Ascoli et al., 2008; Lehmann et al., 2012). Although inhibitory interneurons constitute a clear minority compared to the number of excitatory neurons, they are highly influential, with important roles in cortical maturation, function, plasticity and organization of complex cortical networks underlying a wide range of functions (Lehmann et al., 2012). The majority of these cells in the cortex are inhibitory, and express gamma-aminobutyric acid (GABA) as their principal neurotransmitter (Dreifuss et al., 1969; Somogyi et al., 1983). Further, they have been shown to have an important role in development and function of the cerebral cortex by acting as a sensory "gate" (Gelman and Marin, 2010; Tong et al., 2013), regulating environmental input, and coordinating the output of multiple projection neurons through attenuating and modulating glutamatergic excitation (Levitt, 2005; Lehmann et al., 2012). Inhibitory interneurons may be divided into multiple subtypes on the basis of morphology, physiology, and biochemistry that serve distinct roles in cortical processing (Markram et al., 2004; Rudy et al., 2011). It is estimated that as many of 20 subtypes exist, representing a broad range of morphology and function (Ascoli et al., 2008). For example, studies performed in rodent brain tissue have suggested that these interneurons in the cerebral cortex are typically identified by either characteristic parvalbumin (PV) or somatostatin (SOM) expression (Gonchar and Burkhalter, 1997; Ascoli et al., 2008). PV-positive cells have been implicated in initiation of a critical period for cortical plasticity in the visual, somatosensory and auditory cortices (Hensch et al., 1998; Fagiolini and Hensch, 2000; Hensch, 2004, 2005; Fox and Wong, 2005; Yuste, 2005; Wonders and Anderson, 2006; de Villers-Sidani et al., 2008; Lehmann et al., 2012) and play a critical role in cortical information processing (Tallon-Baudry et al., 1998; Bartos et al., 2007; Cardin et al., 2009; Sohal et al., 2009), whereas SOM-positive cells are believed to plays a role in the acquisition memory and emotional functions (Vecsei and Widerlov, 1990; Schettini, 1991). These two subtypes represent only a fraction of known interneuron subtypes, and of important 
roles that they underlie in the cortex. While slightly less is known about other populations, it is sure that their functional and morphological diversity provides a complex foundation for cortical information processing, and regulating healthy levels of excitation and inhibition in specific cortical sub-circuits.

The study of how these interneurons contribute to ongoing cortical processing is still in its infancy, yet it is believed that their dysfunction contributes to many neurological and neuropsychiatric diseases (Sanacora et al., 2000; McBain and Fisahn, 2001; Levitt et al., 2004; Marin, 2012) such as schizophrenia (Lewis, 2000; Lewis et al., 2005), Alzheimer's disease (Verret et al., 2012; Hazra et al., 2013), epilepsy (Cossart et al., 2001; Levitt, 2005) or autism spectrum disorder (Rubenstein and Merzenich, 2003). Several authors have suggested that a fundamental vulnerability of cortical GABAergic interneurons lies at the heart of these and other disorders, pushing the study of their inherent computational role (and failure thereof) to the forefront (Akbarian et al., 1995; Benes et al., 1996; Rubenstein and Merzenich, 2003; Dani et al., 2005; Levitt, 2005; Lewis et al., 2005; Maffei et al., 2006; Yizhar et al., 2011). Thus, accumulating evidence appears to reflect the crucial role of properly-mediated excitation and inhibition in cortical processing, and highlights the need for better understanding inhibitory circuits. Furthermore, it is critical to explore and document how a chronic increase or decrease in particular inhibitory interneuron populations may affect these processes. However, the study and quantification of interneuron dynamics in neuropathology is complicated by natural fluctuations in their population over the lifecourse (Lehmann et al., 2012). A large number of studies have documented the distribution and numbers of various GABAergic cortical interneurons at single time points in rodents and primates (Fitzpatrick et al., 1987; Hendry et al., 1987; Beaulieu, 1993; see Rudy et al., 2011 and DeFelipe et al., 2013 for review). The trajectory of various interneuron markers has also been examined extensively during early development and early adulthood, primarily in rodent models (Gonchar et al., 2008; Bartolini et al., 2013). Only a handful of studies have however examined the impact of natural aging on the various cortical interneuron subtypes, most of them focusing on a small fraction of the interneuron pool (Miettinen et al., 1993; Bu et al., 2003; Pugliese et al., 2004; see Lehmann et al., 2012 for a review). As these changes strongly lend themselves to understanding the development of age-related inhibition-related disorders, it is thus critical to develop a full picture of how interneurons' populations naturally fluctuate. For this current research, we have elected to study the primary auditory cortex (A1), which plays a key role in auditory learning, speech perception, auditory attention, and cognitive analysis of sound. Like other neocortices, it consists of a layered network of excitatory cells and inhibitory interneurons (Letinic et al., 2002; Molnár et al., 2006; Linden, 2012). Inhibitory interneurons regulate Al's processing by shaping the spectral tuning (Froemke et al., 2007; Wu et al., 2008), temporal tuning (Schulze and Langner, 1999; Razak and Fuzessery, 2009), and response dynamics of local excitatory neurons (Wehr and Zador, 2003). To best conceptualize these inherent lifecourse dynamics, we have documented the distribution of 7 different markers of GABAergic inhibitory interneurons on healthy Long-Evans rats from 9 days (P9) at five time point during the rats' life until advanced maturity at 25 months (P750, equivalent to $\sim 75$ human years based on this strain's longevity). The specific markers we examined include PV, SOM, calretinin (CR), vasoactive intestinal peptide (VIP), neuropeptide-Y (NPY), cholecystokinin (CCK), and choline acetyl transferase (ChAT). Together these markers reveal around $90 \%$ of the overall cortical interneuron population (Gonchar et al., 2008; Xu et al., 2010; Rudy et al., 2011). PV, SOM and CR are useful to divide the interneurons in three mostly non-overlapping groups, which can then be further characterized with the additional markers (Kubota et al., 1994; Gonchar and Burkhalter, 1997; Xu et al., 2004; Butt et al., 2005; Miyoshi et al., 2007). Patterns of GABA and neuron-specific Nissl staining were also documented at each time point to determine the trajectories of inhibitory interneurons and cortical neurons as a whole. Using this information, we constructed a simple graphical model, which may be applied as a framework for creating more advanced simulations of interneuronal implication in normal cerebral processing, normal aging, or pathological processes.

\section{MATERIALS AND METHODS ANIMALS}

Experiments were performed in auditory cortex (A1) of LongEvans rats between postnatal day 9 (P9) and P750 $(\sim 25$ months). All experimental protocols were approved by the Montreal Neurological Institute Animal Care Committee and complied with the guidelines of the Canadian Council on Animal Care.

\section{PREPARATION AND DETERMINATION OF A1 BORDERS}

All rats were first anaesthetized with pentobarbital ( $85 \mathrm{mg} / \mathrm{kg}$ i.p.) and then perfused through the heart with phosphate buffered saline ( $\mathrm{pH} 7.4$, PBS) followed by paraformaldehyde (4\%) in $0.1 \mathrm{M}$ PBS. Their brains were removed from the skulls, postfixed in the same fixative overnight and transferred to a $30 \%$ sucrose solution, snap-frozen, and stored at $-80^{\circ} \mathrm{C}$ until sectioning. Fixed material was sectioned on a freezing microtome at a $40 \mu \mathrm{m}$ thickness in the coronal plane along the tonotopic axis of A1. The boundaries of the primary auditory cortex were functionally determined in a subset of animals of different ages with intracortical recordings as previously done (Bao et al., 2003; de Villers-Sidani et al., 2007) using the following criteria: (1) primary auditory neurons generally have a continuous, single-peaked, V-shaped receptive field, and (2) characteristic frequencies of the A1 neurons are tonotopically organized with high frequencies represented rostrally and low frequencies represented caudally. At the end of the recording session, the location of the electrode tracks was converted to coordinates in the Paxinos rat brain atlas. Functional mapping was performed in at least one animal at every age examined except for P9 where tone-evoked responses cannot yet be obtained. For that group, the location of A1 was determined based on mapping done at P12. The cortical borders were defined according to the cell size, density and depth as in (Games and Winer, 1988): layer I $(0-175 \mu \mathrm{m})$, layers II-III $(175-500 \mu \mathrm{m})$, layer IV $(500-700 \mu \mathrm{m})$, and layers V-VI $(700-1200 \mu \mathrm{m})$. A photomicrograph of the whole cortical thickness showing the border of these cortical layers is shown in Figure 1. For the cell count analysis, 
A

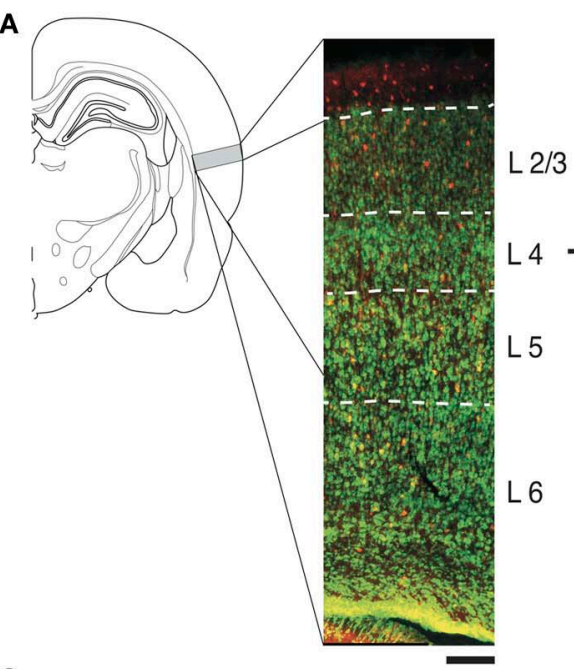

C

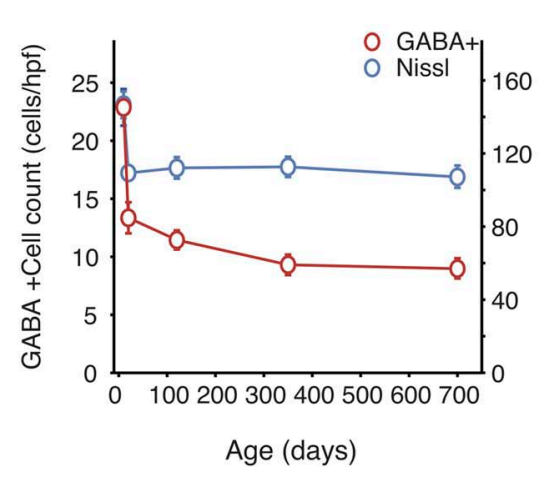

FIGURE 1 | Total GABAergic cell count and global neuron count across the lifespan in A1. (A) Left, Schematic representation of the location of A1 in the rat brain and, right, low power confocal photomicrograph (10X) showing a representative section of the full thickness of $A 1$ (pia up) with cortical layer borders. Neuron-specific Nissl staining is shown in green and GABA staining in red. Scale bar: $100 \mu \mathrm{m}$. (B) Representative high power
B

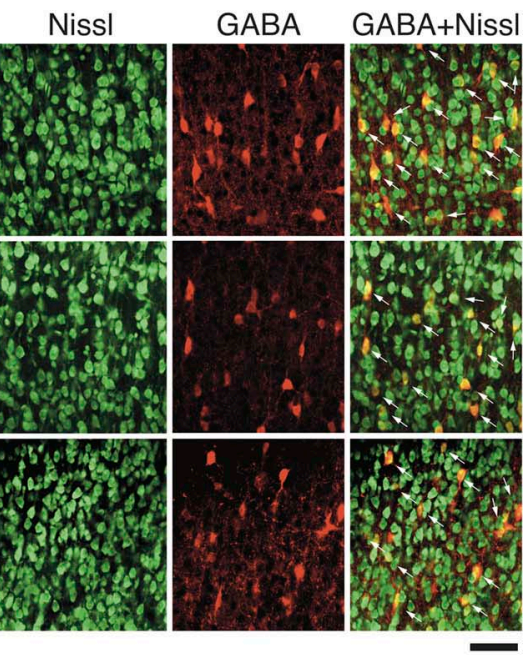

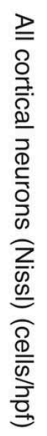

micrographs of immunolabeled GABAergic cortical interneurons (red) and Nissl-stained cell bodies (green) and their overlap (yellow with arrow) at three age points. Scale bar: $50 \mu \mathrm{m}$. (C) GABA immunolabeled cell count and total neural cell count average across all cortical layers over time ( $n=28$ animals with 21 photomicrographs per animal for each marker). Error bars are s.e.m.
21 photomicrographs were taken in each animal at random locations within the borders of A1 with on average equal sampling in all cortical layers.

\section{IMMUNOHISTOCHEMISTRY}

Sections were treated with PBS $0.1 \mathrm{M} 3 \times 5 \mathrm{~min}$, followed by mixture of gelatine (2\%) and triton X-100 (0.25\%) in PBS (PBS-GT) for $4 \times 10 \mathrm{~min}$, transferred into primary antibody solution containing PBS-GT and incubated $24-48 \mathrm{~h}$. After incubation, the sections were washed in blocking buffer PBS-GT and incubated for $1 \mathrm{~h}$ in dilutions of secondary antibody conjugated with different fluorophores. All primary and secondary antibodies used (see below) were tested for optimal conditions for single and double labeling. The following primary antibodies were used: (1) rabbit anti-gamma amino butyric acid (GABA; Sigma \#A2052, 1:5000), (2) mouse anti-PV-19 (Sigma \#P3088, 1:10,000), (3) goat anti-CR (Swant \#CG1, 1:1000), (4) rat anti-SOM-14 (Chemicon \#MAB354, Temecula, CA, 1:1000), (5) rabbit anti-CCK (code L424, a gift from Dr Andrea Varro, Department of physiology,
University of Liverpool; see Morino et al., 1994), (6) guinea pig anti-VIP (Peninsula Laboratories \#T5030, 1:10,000), (7) guinea pig anti-NPY (Abcam \#ab10341, 1:500) (synthetic peptide corresponding to amino acids 76-91 of rat neuropeptide $\mathrm{Y}$ ), (8) goat anti-ChAT (Chemicon \#AB144P, 1:100), and (9) the neuron specific NeuroTrace fluorescent Nissl stain (Molecular Probes \#N21480, 1:300). The secondary antibodies were: (1) donkey anti-rabbit (conjugated to Cy3, 1:800, Jackson ImmunoResearch, West Grove, PA; conjugated to AlexaFluor (AF) 488 and 647, 1:800, Jackson) (2) donkey anti-mouse (Cy3, Jackson, 1:800; AF488, Jackson, 1:800; AF647, Invitrogen, 1:800) (3) donkey antirat (AF488, Jackson, 1:800) (4) donkey anti-guinea pig (AF488, Jackson, 1:800), and (5) goat anti-rat (AF488, Jackson, 1:800). Stained sections were mounted on $1 \%$ gelatin-coated slides, air-dried and cover slipped with mowiol solution (Tris $0.2 \mathrm{M}$, $30 \%$ glycerol, $12 \%$ mowiol). Rat tissue from different ages were immunostained in pairs to limit variability related to antibody fixation, incubation time, and postsectioning condition of tissues. 


\section{MICROSCOPY, IMAGE ACQUISITION AND DATA ANALYSIS}

A Zeiss LSM 510 Meta confocal microscope equipped with filter for green Cy2/AF488, red CY3 and infrared CY5/AF647 was used to assess fluorescence in the immunostained sections. To locate A1 in non-functionally mapped animals we used the stereotaxic coordinates (Paxinos): interaural between 5.76 and $2.16 \mathrm{~mm}$ and Bregma between -3.24 and $-6.84 \mathrm{~mm}$ (see above section on determination of A1 borders). To quantify the positive cells, 21 digital images of A1 cortical sections were taken with a $40 \mathrm{X}$ objective (Zeiss LSM 510) at random locations within each A1 of each hemisphere for each animal. All quantifications were assessed in 400-500 $\mu \mathrm{m}$ wide A1 sectors (the approximate width of A1 on coronal sections) per hemisphere extending from layer 1 to the underlying white matter. Confocal images were thresholded and adjusted for brightness to maximize the dynamic range of each channel using ImageJ (http://rsb.info.nih.gov/ij/) and adobe Photoshop CS5 (Adobe, San Jose, CA). The goal of our quantitative analyses was to determine the percentage of different subtypes of GABAergic neurons in the auditory cortex (A1) for different age. We determined the number of immune-labeled cells in each section of A1 at different ages (P9, P20, P120, P350, and P700-750) using the optical dissector method (StereoInvestigator software MBF bioscience, Williston, VT) to avoid biased sampling. These counts were then pooled and adjusted to reflect what would have been counted in the whole 40X field. Data were then recorded as an averaged value per high power field (hfp) for each animal and age group. All cells displaying labeling above background levels were counted, regardless of their staining intensity. Data from both hemispheres was pooled. An observer blind to the age of the animal performed all cell counts. Regression analysis was performed in the MatLab environment (Natick, MA) and using the least square methods. Statistical significance between the different age groups and for curve fitting was assessed using ANOVA analysis and the F-test. Unless stated otherwise, data are presented as mean \pm standard error to the mean (s.e.m).

\section{RESULTS}

\section{CHANGES OF GABAergic INHIBITORY INTERNEURONS WITH AGING}

Our first results using markers for PV, SOM, CR, VIP, ChAT, NPY, and CCK revealed that GABAergic interneuron populations in A1 of rats from 9 to 750 days of age showed considerable fluctuation with time. Surprisingly, we found that even though there was considerable variance between different populations at different time points, the total number of cortical neuron and inhibitory neurons as evidenced by neuron specific Nissl and GABA staining decrease rapidly before postnatal day 20 (P20), by 41 and $77 \%$ respectively but afterward remained unchanged (Nissl: from $155 \pm 5$ to $110 \pm 4$ cells/hpf; $p<0.001$; GABA: from $24 \pm 3$ to $13 \pm 2$ cells/hpf; $p<0.001$; Figure 1 ). Thus, GABA positive cells saw their overall representation in the neuronal pool fall from 16 to $12 \%$ over that time period. Since GABA counts remain relatively stable after $\mathrm{P} 20$, its relatively small decline later in life cannot account for the global fluctuations in interneuron markers we observed. These results mirror with studies by Pinto et al. (2010) that confirmed that the basal pool of GABA in human is relatively maintained across the lifespan. However, this finding also indicates that some interneuron subtypes may up- or down-regulate expression of certain markers, perhaps compensating for changes in cortical networks resulting from learning or degeneration. Letzkus et al. (2011) have previously suggested this mechanism, in part of a wider mechanism of cortical disinhibition. To further investigate this possibility, we decided to look more closely at different GABAergic populations at different time points.

To study A1 at different ages, our samples were binned into 5 time points: immature cortex (P9), prior to critical period development and the development of functional inhibition in A1 (Chang et al., 2005; de Villers-Sidani and Merzenich, 2011), developing A1 postcritical period closure (P20), a young adult cortex (P120) with a plateau of interneurons population, older adult cortex point (P350) and aged cortex (P700-750). GABA co-labeling was also examined for all interneuron markers at all ages and except for one exception (see CR results below), all cells positive for one of the markers examined were also GABA immunoreactive (see Figures 1-4). Given this finding, GABA co-staining ratios are not presented in detail below.

At P9, CR, VIP, and ChAT appeared to be the most prominent cortical interneuron markers; representing 10, 8 , and $1 \%$ of total GABA positive cells (see Figure 2). This finding may be explained by delayed postnatal development of the most common markers in adults, PV, SOM, NPY and CCK, which were still minimally expressed in that second week of age. In previous studies focusing on the visual cortex, ChAT has been found to invariably co-localize to cells expressing VIP (Gonchar et al., 2008). We examined here if it was also the case in A1 and found that, at all ages, only $\sim 50 \%$ of ChAT + were also VIP $+(48 \pm$ $6 \%$; Figure 2). We also found that a subset $\mathrm{CR}+$ cells at $\mathrm{P} 9$ were GABA $-(24 \pm 6 \%)$ whereas all of them were GABA+ at later ages. Between P9 and P20, we documented a significant 52\% reduction in CR expression ( $2.9 \pm 0.5$ to $1.3 \pm 0.3$ cells/hpf; $p=0.008$; Figure 2) and the appearance of CCK and SOM positive cells in A1 (CCK: from 0 to $0.57 \pm 0.2$ cells/hpf; $p<0.001$; Figure 3; SOM: from $0.2 \pm 0.03$ to $1.4 \pm 0.2$ cells/hpf; $p<0.001$; Figure 4 ). Interestingly, $\mathrm{CR}$ counts relative to the entire interneuron population were maintained despite the decrease in their absolute count in A1. This finding may be related to the $47 \%$ reduction in global GABA + cells counts over the same time period. Another notable change between P9 and P20 was the significant 450\% expansion of the PV cell population ( $p<0.001$; Figure 4$)$. At P20, as seen in Figures 5, 6, PV+ cells became by far the dominant interneuron in A1 representing around $35 \%$ of the overall population followed by the CR (10\%) and VIP (18\%) populations.

Many interneurons had reached stable adult levels by P120 and showed minimal or no significant change in their marker expression from P20. That was the case for CCK, CR, ChAT, and PV (no change) and VIP $(2.6 \pm 0.3$ to $1.8 \pm 0.4$ cells/hpf; $p=0.05)$. SOM + cell counts however continued to increase and reached their lifetime maximum at around P120 $(\sim 100 \%$ increase to $2.75 \pm 0.2 ; p=0.01$; Figure 4). NPY expression also steadily increased from P20 to P120 by more than three-fold $(0.19 \pm 0.04$ to $0.74 \pm 0.3$ cells/hpf; $p=0.03$; Figure 3$)$. At this age the dominant interneuron population remained $\mathrm{PV}$ at $45 \%$ followed by SOM at $32 \%$ (see Figure 6). The relative population 


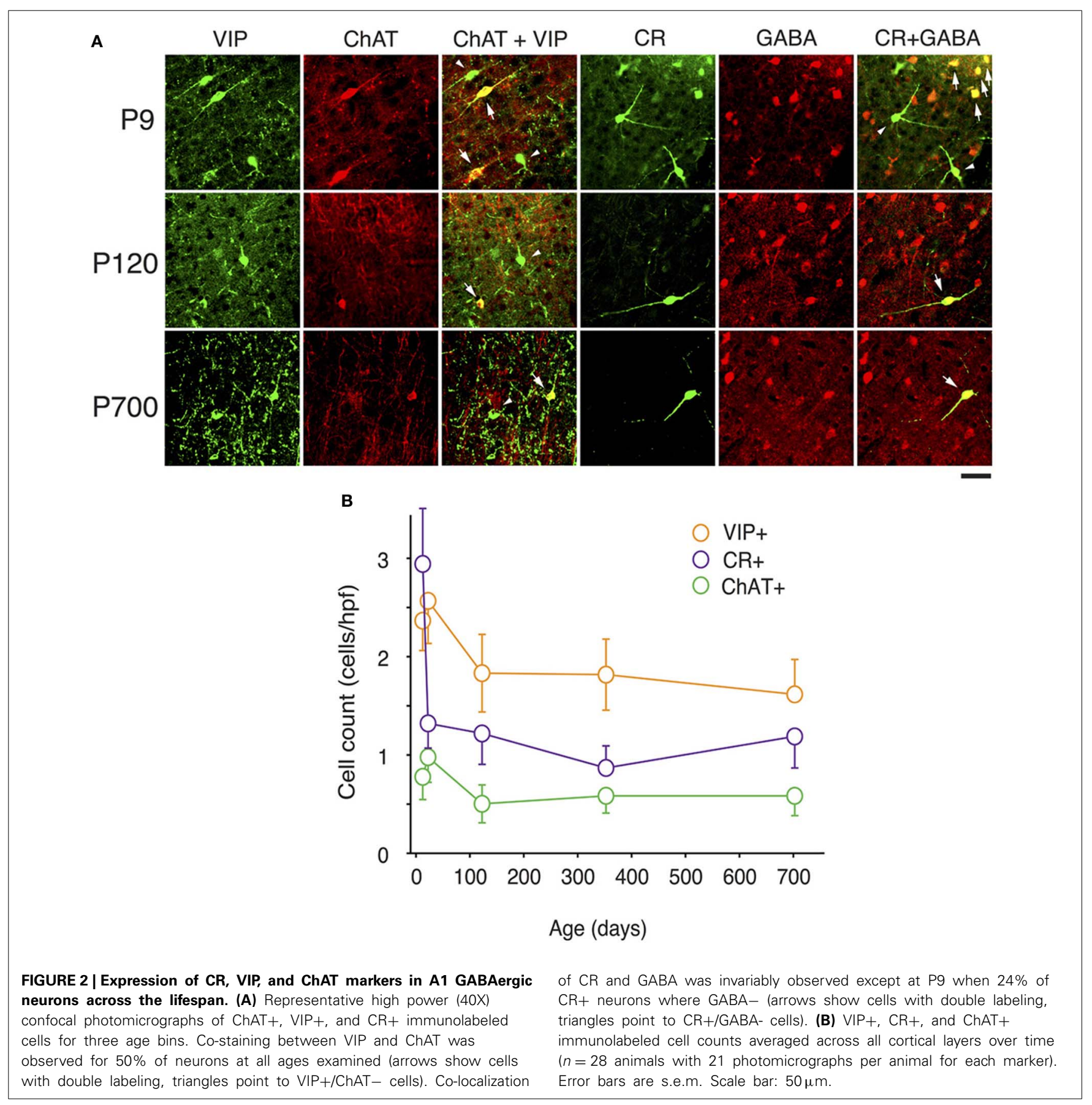

of the other interneuron markers changed only marginally during that period despite the significant 19\% decrease in GABA+ cells between P20 and P120 ( $p=0.002$; Figure 1). These changes somewhat contrasted with what we observed in the P120-350 interval when the animals reached midlife. During that period we observed a substantial $\sim 50 \%$ decrease in SOM expression (down to $1.5 \pm 0.3$ cells/hpf; $p=0.04$; Figure 4) and a continued increase of NPY+ cells (up to $1.1 \pm 0.3$ cells/hpf; $p=0.04$; Figure 3). By P350 SOM cells made up only $21 \%$ of the interneuron pool and NPY cells were almost as numerous at $18 \%$ of all interneurons (see Figures 5, 6). The total number of GABA+ cells also decreased by $\sim 20 \%(12.1 \pm 0.3$ to $9.6 \pm 0.2$ cells $/ \mathrm{hpf}$; $p=0.02$; Figure 1) during the same period, a change that cannot be fully explained the trajectories of SOM or NPY cells which are to few in absolute numbers to influence global GABA counts to this extent. As the animals grew into old age, the same trends continued including a further reduction in SOM+ cells (down to $0.9 \pm 0.3$ cells/hpf; $p=0.009$; Figure 4 ), now not significantly different from their P20 value, and a further $\sim 20 \%$ increase in NPY immunostaining ( $p=0.04$; Figure 3). During that later life period PV + cell counts also declined significantly by $23 \%$ ( $p=$ 0.02 ; Figure 4). Total GABA+ and Nissl+ cell counts remained 


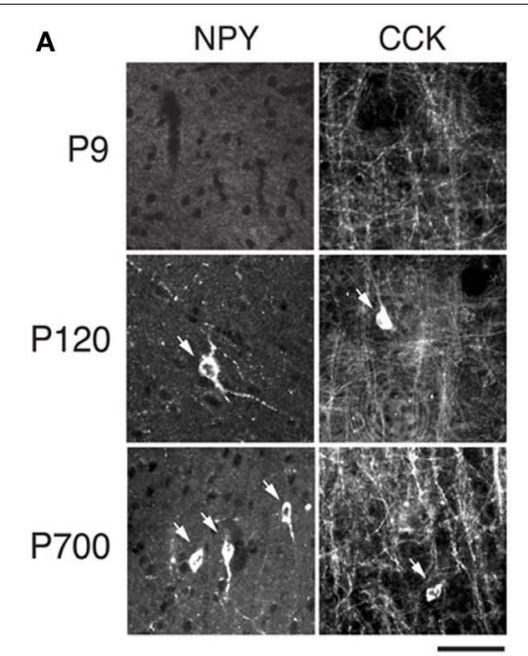

FIGURE 3 | Changes in NPY and CCK expression in A1 during life. (A) Representative high power micrographs of NPY + (left) and CCK+ immunolabeled cells (right) at three age intervals. The arrows mark the

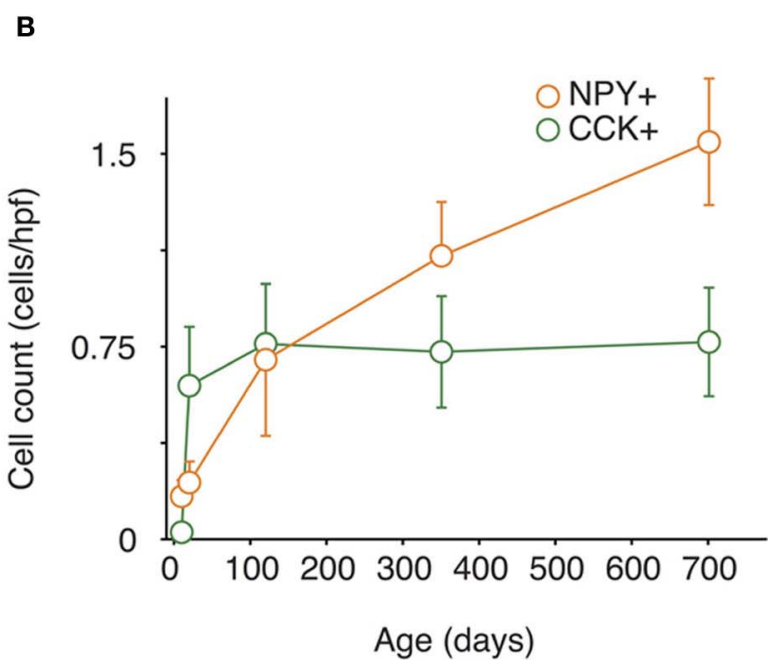

immunoreactive cells (B) NPY + and CCK + immunolabeled cell counts averaged across all cortical layers over time ( $n=28$ animals with 21 photomicrographs per animal for each marker). Error bars are s.e.m. Scale bar $=50 \mu \mathrm{m}$. stable between P350 and P700, indicating against the changes in PV, SOM and NPY expression are to some extent independent from GABA staining fluctuations. It is important to note that all neurons taken together, these percentages add up to more than $100 \%$, confirming that individual neurons express multiple markers and that the same neurons may have been were counted more than once for different markers (DeFelipe, 1993; Yan et al., 1995; Del Rio and DeFelipe, 1997; Kowiański et al., 2004; Xu et al., 2006; Gonchar et al., 2008). A summary of the different interneuron marker counts at all ages is found in Table $\mathbf{1 .}$

\section{LAYER-BASED DISTRIBUTION OF GABAergic INHIBITORY INTERNEURONS}

Previous findings have suggested that interneuron origins, and rates of maturation, differentiation and specification can be correlated with laminar location (Anderson et al., 2002; Valcanis and Tan, 2003). Therefore, in order to create a detailed model of interneuron marker expression across the lifecourse, we quantified their presence in different layers. Figures 1, 5, 6 show how GABAergic interneuron populations were divided by layer, and how a proportion of these cells vary with time. Across all ages and layers, the largest overall population still appears to PV-expressing cells. SOM cells represented the second highest proportion of cells, but their numbers were largely dwarfed by their PV counterparts. Due to their proposed roles in cortical synchronization (Somogyi and Klausberger, 2005; Bartos et al., 2007), plasticity (Beierlein et al., 2000; Fries et al., 2002), and reported decline with aging (Kamal et al., 2013), we decided to examine these two groups of cells more closely.

We observed no SOM+ cells and only minimal staining for PV at P9, which was restricted to layers 2-4. The bulk of PV expression occurred as stated above between P9 and P20 with 2/3 of cells located in the thalamorecipient layer 4 . SOM+ cells followed a very similar pattern and more than $50 \%$ were also located primarily in layer 4 at P9. For both of these cell types the main change between P20 and P120 was a significant increase in their populations in output layers 5/6 (PV: 50\% increase; $p=0.01$; SOM: 290\% increase; $p<0.001$; Figure 6). No significant change in PV counts was detected between P120 and P350, as expected from the global cell counts. As reported above, the total SOM population significantly declines between P120 and P350. This change is primarily the result of a $50 \%$ disappearance of these cells in superficial layers $2 / 3$. No significant change in SOM was noted in the other layers during that period. Continuing to later life it was layers 5/6 that saw the greatest changes in both PV and SOM cells which were reduced by $32 \%(p=0.02$; Figure 6) and $60 \%$ ( $p=006$; Figure 6), respectively. At P350 both PV and SOM levels in layer 4 remain equivalent to P20-120 levels $(p>0.2)$.

Also in agreement with earlier studies in mouse (Gonchar et al., 2008), there were layer-based changes in cells expressing other neuropeptides (CR, VIP, ChAT). These three markers are all present at $\mathrm{P} 9$ and more prominently expressed in the more superficial cortical layers $2 / 3$ and 4 . This pattern is largely conserved throughout the life of the animal despite the proportional increase in each of those markers related to the loss of GABA+ non-otherwise marked cells during the P9-P20 period (Figure 5). CCK + cells, which are first seen in A1 between P9 and P20, appear homogeneously over all cortical layers. Their population keeps increasing over the next 100 days but only in superficial layers $2 / 3$ (310\% increase; $p<0.001$; Figure 5). Their counts then remain stable in all layers until P700. NPY expressing neurons, the only one that keep growing from birth to old age showed a similar overall layer specific pattern with earlier expression in deeper cortical layers. At P20, no NPY cells were found in layers $2 / 3$. By P120, NPY expression reached a plateau in layers $4-6$ but expression in layers $2 / 3$ kept increasing up to P700 when they represented $18 \%$ of all interneurons in those layers (200\% increase between P120 and P700; $p=0.01$; Figure 5). Thus, it seems that 


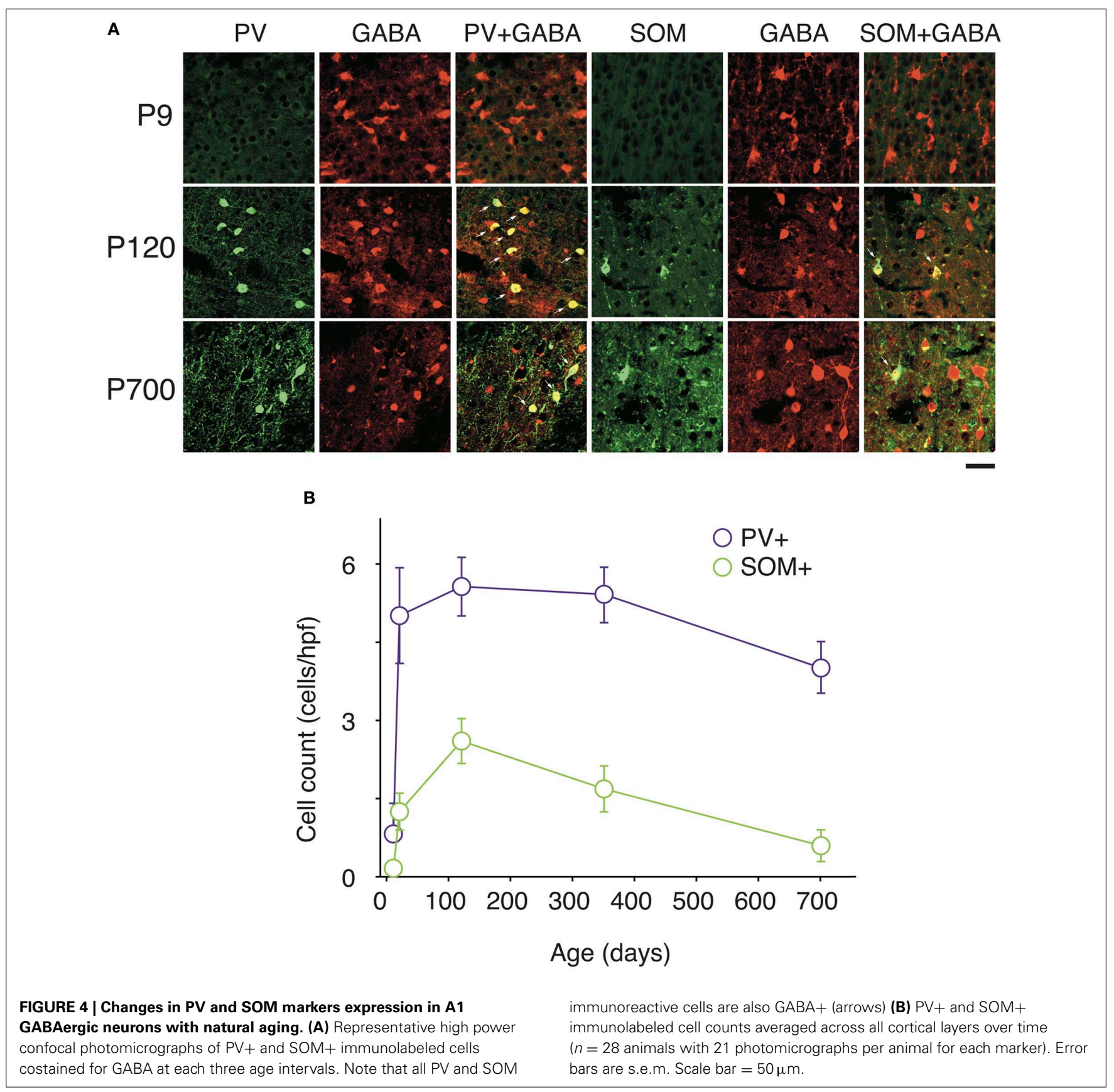

both CCK and NPY+ cells, as well as those expressing PV and SOM have complex layer-based changes over the course of an animal's life and our earlier-predicted trajectory for the global population of GABAergic neurons in A1 cannot account for these. This limitation, as well as its possible implications will be further explored in the discussion section.

\section{ANALYSIS OF THE TRAJECTORY OF THE DIFFERENT INTERNEURON POPULATIONS DURING LIFE}

As highlighted in the paragraphs above not all interneuron subtypes demonstrated comparable patterns of development and disappearance. To further characterize these trajectories we performed a regression analysis on each of them to determine what type of function would best describe their behavior during development adulthood and aging. Based on goodness of fit measures (Table 2), we first determined that the variation in interneuron markers could be reasonably well described by an exponential decay function in the first 150 days of life whereas a linear function was a better fit for P150-750. Based on these exponential functions we could then compute the time for each interneuron marker to reach their limiting value (asymptote) and time constant $\left(\mathrm{T}_{1 / 2}\right)$ during development (Table 3 ). Figure 7 shows the data points and functions obtained for each interneuron marker. Overall we identified four distinct behaviors in the 

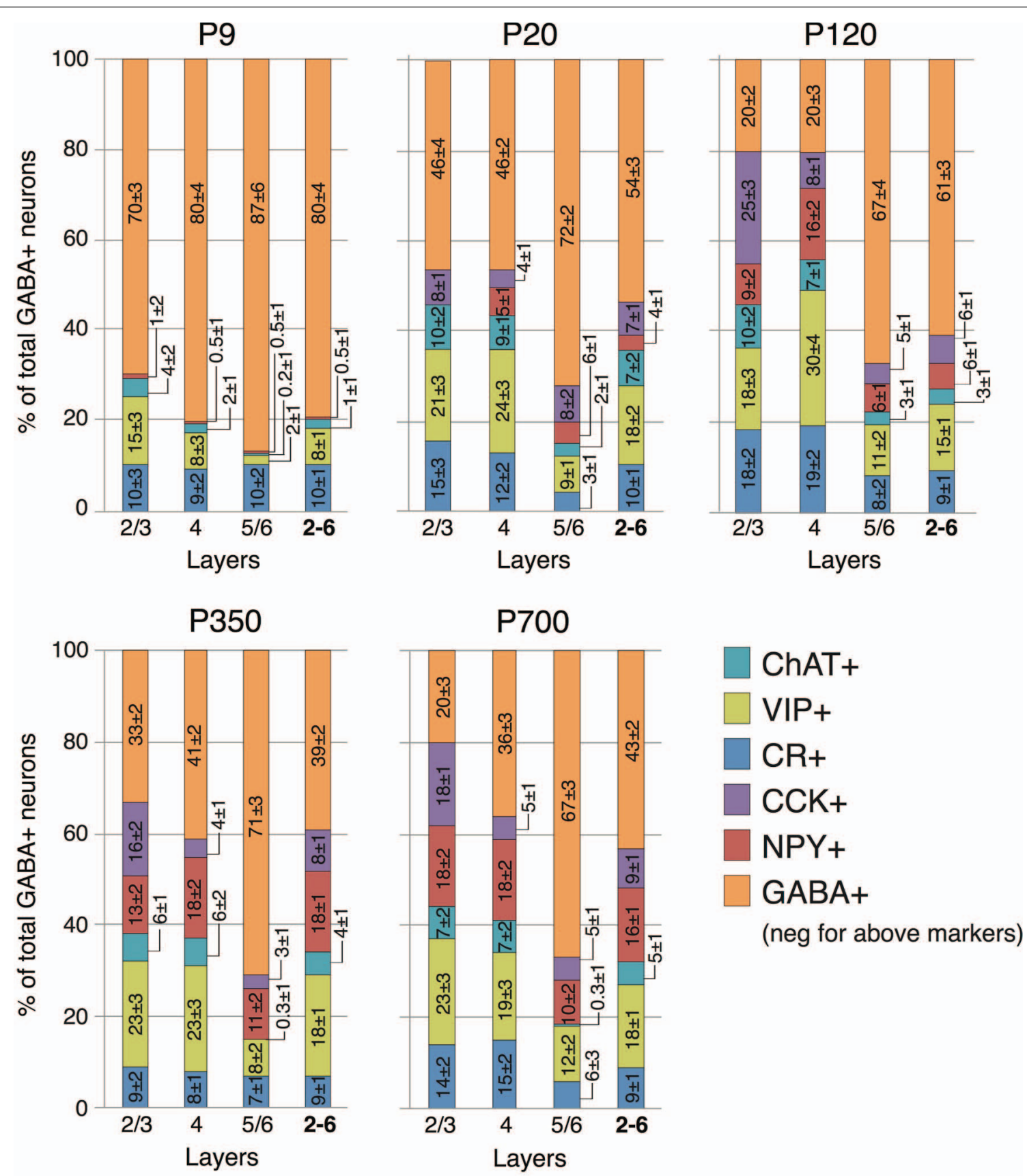

FIGURE 5 | Laminar distribution of CR, VIP, ChAT, NPY, and CCK neuron markers according to age. Numbers represent the percentage of cells immunostained for the various interneuron markers relative to the total
$\mathrm{GABA}+$ cells count \pm s.e.m. Orange GABA+ bars represent the percentage of cells immunoreactive for GABA but not showing co-staining for CR, VIP, ChAT, NPY, or CCK. interneurons studied. Three types of interneurons (CR, VIP, and ChAT) displayed an exponential decay and had no significant change in their counts up to very old age. The rate of decay significantly differed between these 3 cell counts that stabilized at around P35, P90, and P140, respectively. All other counts (NPY, CCK, PV, and SOM) followed an inverse exponential decay during early development. PV+ and CCK + cell counts both reached a plateau between 30 and 40 days of age whereas NPY+ and
SOM+ ells stabilized later at around P145. In the P150-700 period CCK+ neuron counts remained very stable but both PV+ and SOM+ cells, as described previously, steadily decreased from P150 and after. Confirming our earlier results, the linear function fitted to NPY measurements is consistent with a progressive increase in their expression throughout the lifespan. Finally, we analyzed the variation in total A1 neuron (Nissl+) and interneuron populations $(\mathrm{GABA}+)$ using the same type of regression 

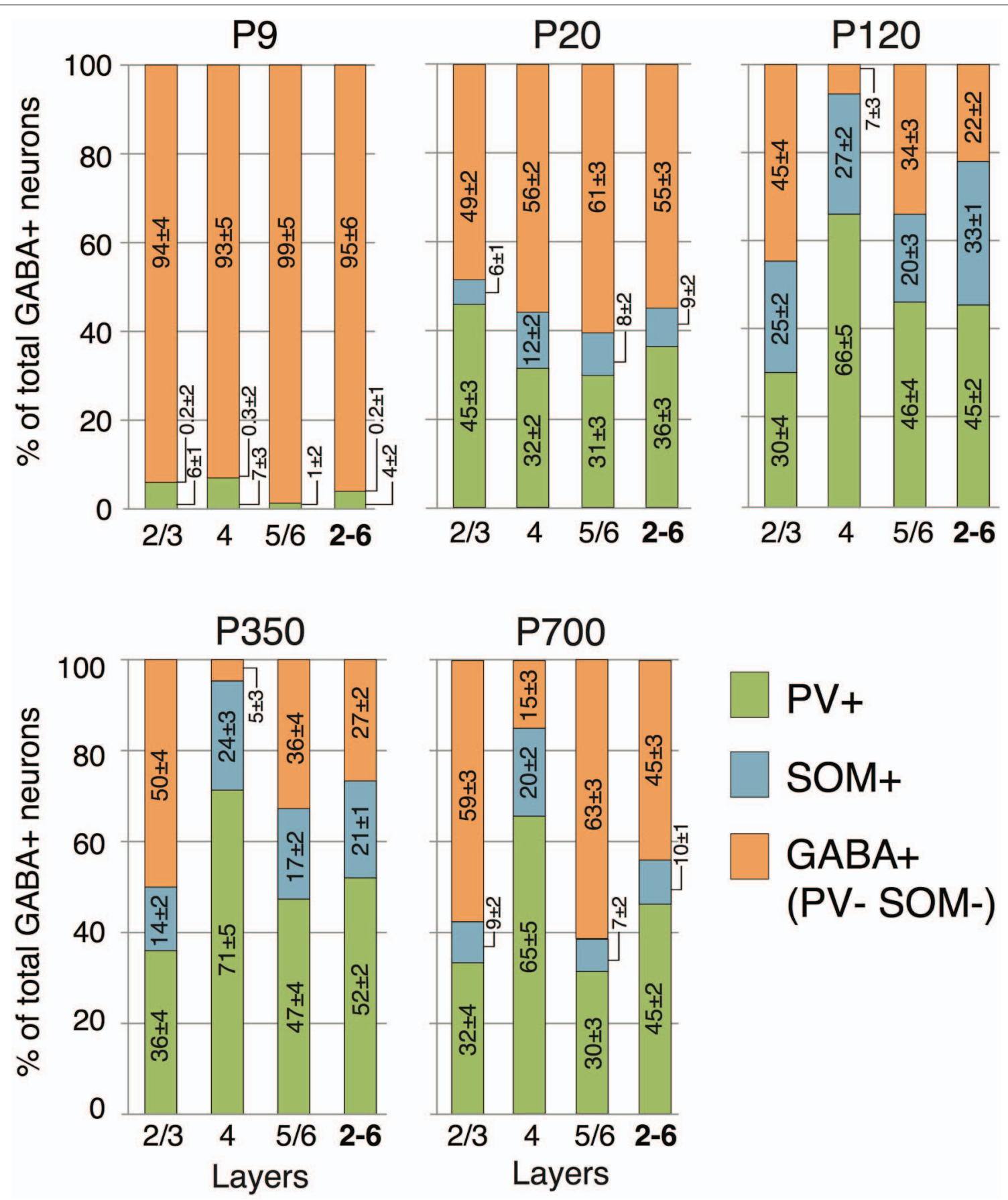

FIGURE 6 | Laminar distribution of PV and SOM neuron markers according to age. Numbers reported in the columns represent the percentage of cells immunostained relative to the total GABA+ cells count \pm s.e.m. Orange GABA+ bars represent the percentage of cells immunoreactive for GABA but not showing co-staining for either PV or SOM. analysis. Both of these datasets followed an exponential decay similar to CR+ VIP+, and ChAT + cells that stabilized at around P35-40. Nissl staining remained overall very stable over time and GABA + showed a barely significant downward trend after P150. It should be noted that all cells positive for CR, VIP, ChAT, NPY, CCK, PV, and SOM were also GABA+ at all ages confirming their status as inhibitory interneurons. In conclusion, it appears that the majority of cortical interneuron changes after P150 were mediated by changing expression of $\mathrm{PV}-, \mathrm{SOM}-$, and NPYexpressing cells. Thus, with ours observations, we have established diverse patterns of GABAergic neurons development and disappearance over an animal's lifecourse. 


\section{DISCUSSION}

Using immuonolabeling techniques, we have examined various populations of GABAergic interneurons in the rat auditory cortex across the animal's ordinary lifespan. In this study, neurons expressing PV, CR, SOM, VIP, NPY, CCK, and ChAT were

Table 1 | Relative percentage of the interneuron markers examined in A1 at different ages.

\begin{tabular}{|c|c|c|c|c|c|}
\hline \multirow[t]{2}{*}{ Markers } & \multicolumn{5}{|c|}{$\begin{array}{l}\text { Mean } \pm S D \text { percent of GABAergic neurons in } \\
\text { all layers }\end{array}$} \\
\hline & P9 & P20 & P120 & P350 & P700 \\
\hline GABA & 100 & 100 & 100 & 100 & 100 \\
\hline PV & $4 \pm 2$ & $36 \pm 3$ & $45 \pm 2$ & $52 \pm 2$ & $45 \pm 2$ \\
\hline SOM & $0.2 \pm 1$ & $9 \pm 2$ & $33 \pm 1$ & $21 \pm 1$ & $10 \pm 1$ \\
\hline $\mathrm{CR}$ & $10 \pm 1$ & $10 \pm 1$ & $9 \pm 1$ & $9 \pm 1$ & $9 \pm 1$ \\
\hline VIP & $8 \pm 1$ & $18 \pm 2$ & $15 \pm 1$ & $18 \pm 1$ & $18 \pm 1$ \\
\hline ChAT & $1 \pm 1$ & $7 \pm 2$ & $3 \pm 1$ & $4 \pm 1$ & $5 \pm 1$ \\
\hline NPY & $0.5 \pm 1$ & $4 \pm 1$ & $6 \pm 1$ & $18 \pm 1$ & $16 \pm 1$ \\
\hline CCK & $0 \pm 1$ & $7 \pm 1$ & $6 \pm 1$ & $8 \pm 1$ & $9 \pm 1$ \\
\hline
\end{tabular}

monitored at 5 different time points, and across cortical layers. In addition to fluctuation in expression of many of our markers changed across the lifespan, it was found through Nissl staining that the total number neurons in the cortex appeared to decrease especially during early development. Findings by Burianova et al. (2009) have shown a robust age-related decrease in markers for GABAergic cells, suggesting that this decrease may be organized, in large part, by inhibitory interneurons. In agreement with this possibility, we have found numerous lines of evidence to suggest that programmed GABAergic cell death in a variety of interneuron populations death may, in fact, provide an integral part of cortical changes (thus, by extension, excitability) across the life course. The most notable instance of this was the robust decrease in CR, VIP and ChAT cell markers before P20. While seemingly a large and indiscriminate cell death programmed, this time point, in fact coincides with the beginning of mature sounds representation in A1 (de Villers-Sidani et al., 2008). This tightly controlled process, relying on a tight balance of excitation and inhibition is essential for mature cortical function, and depends heavily on both environmental input and neurochemical environment (de Villers-Sidani and Merzenich, 2011; Anomal

Table 2 | Goodness of fit values for all functions describing the trajectory of the neural markers examined during development (P9-150) and aging (P150-750).

\begin{tabular}{|c|c|c|c|c|c|c|c|c|c|c|}
\hline \multirow[t]{2}{*}{ Neuron markers } & \multicolumn{5}{|c|}{ P9-150 } & \multicolumn{5}{|c|}{ P150-750 } \\
\hline & $\begin{array}{l}\text { RMSE of exponential } \\
\text { function }\end{array}$ & $R^{2}$ & $d f$ & $f$-value & $P$-value & $\begin{array}{l}\text { RMSE of linear } \\
\text { function }\end{array}$ & $R^{2}$ & $d f$ & $f$-value & $P$-value \\
\hline PV & 0.4949 & 0.93 & 15 & 200 & $<0.0001$ & 0.6030 & 0.56 & 15 & 19.9 & 0.0005 \\
\hline SOM & 0.5634 & 0.65 & 15 & 28.4 & 0.0001 & 0.4782 & 0.73 & 15 & 40.6 & $<0.0001$ \\
\hline $\mathrm{CR}$ & 0.3448 & 0.84 & 15 & 122 & $<0.0001$ & 0.3147 & 0.023 & 15 & 1.36 & 0.263 \\
\hline VIP & 0.2917 & 0.51 & 15 & 17.6 & 0.0011 & 0.2732 & 0.065 & 15 & 0.09 & 0.769 \\
\hline ChAT & 0.2166 & 0.42 & 15 & 11.2 & 0.0052 & 0.1656 & 0.070 & 15 & 0.02 & 0.890 \\
\hline NPY & 0.1120 & 0.83 & 15 & 78.1 & $<0.0001$ & 0.1653 & 0.68 & 15 & 33.6 & $<0.0001$ \\
\hline CCK & 0.0578 & 0.97 & 15 & 390 & $<0.0001$ & 0.0758 & 0.0033 & 15 & 0.95 & 0.35 \\
\hline GABA & 1.5437 & 0.90 & 15 & 118 & $<0.0001$ & 1.0550 & 0.19 & 15 & 4.45 & 0.06 \\
\hline Nissl & 6.9281 & 0.80 & 15 & 590 & $<0.0001$ & 3.2404 & 0.0071 & 15 & 0.01 & 0.92 \\
\hline
\end{tabular}

RMSE stands for root mean square error.

Table 3 | Summary of the main characteristics of all functions describing the trajectory of the neural markers examined.

\begin{tabular}{|c|c|c|c|}
\hline $\begin{array}{l}\text { Neurons } \\
\text { subclasses }\end{array}$ & $\begin{array}{l}\text { Time constant of exponential decay }\left(t \frac{1}{2} ;\right. \\
\text { days } \pm 95 \% \text { confidence intervals) }\end{array}$ & $\begin{array}{c}\text { Time at } 1 \% \text { of asymptote } \\
\text { value (days) }\end{array}$ & $\begin{array}{c}\text { Rate of change of linear function (slope; cell per } \\
\text { hpf/day } \pm 95 \% \text { confidence intervals) }\end{array}$ \\
\hline \multicolumn{4}{|c|}{ EXPONENTIAL DECAY AND PLATEAU } \\
\hline CR & $4.05 \pm 1.77$ & 34 & $0.00043 \pm 0.00078$ \\
\hline VIP & $82.3 \pm 21.2$ & 143 & $9.28 e-5 \pm 0.00041$ \\
\hline ChAT & $17.9 \pm 4.26$ & 91 & $-2.97 e-5 \pm 0.00041$ \\
\hline \multicolumn{4}{|c|}{ EXPONENTIAL DECAY FOLLOWED BY LINEAR DECREASE } \\
\hline PV & $4.41 \pm 1.56$ & 30 & $-0.0031 \pm 0.0015$ \\
\hline SOM & $56.1 \pm 16.6$ & 144 & $-0.0035 \pm 0.0012$ \\
\hline \multicolumn{4}{|c|}{ INVERSE EXPONENTIAL DECAY AND PLATEAU } \\
\hline CCK & $6.42 \pm 3.21$ & 40 & $-8.59 e-5 \pm 0.00019$ \\
\hline \multicolumn{4}{|c|}{ INVERSE EXPONENTIAL DECAY AND LINEAR INCREASE } \\
\hline NPY & $59.3 \pm 20.8$ & 145 & $0.0011 \pm 0.000041$ \\
\hline \multicolumn{4}{|c|}{ GLOBAL A1 CELL POPULATION } \\
\hline GABA & $5.73 \pm 1.96$ & 38 & $-0.0026 \pm 0.0027$ \\
\hline Nissl & $7.68 \pm 2.36$ & 36 & $-0.00042 \pm 0.0081$ \\
\hline
\end{tabular}




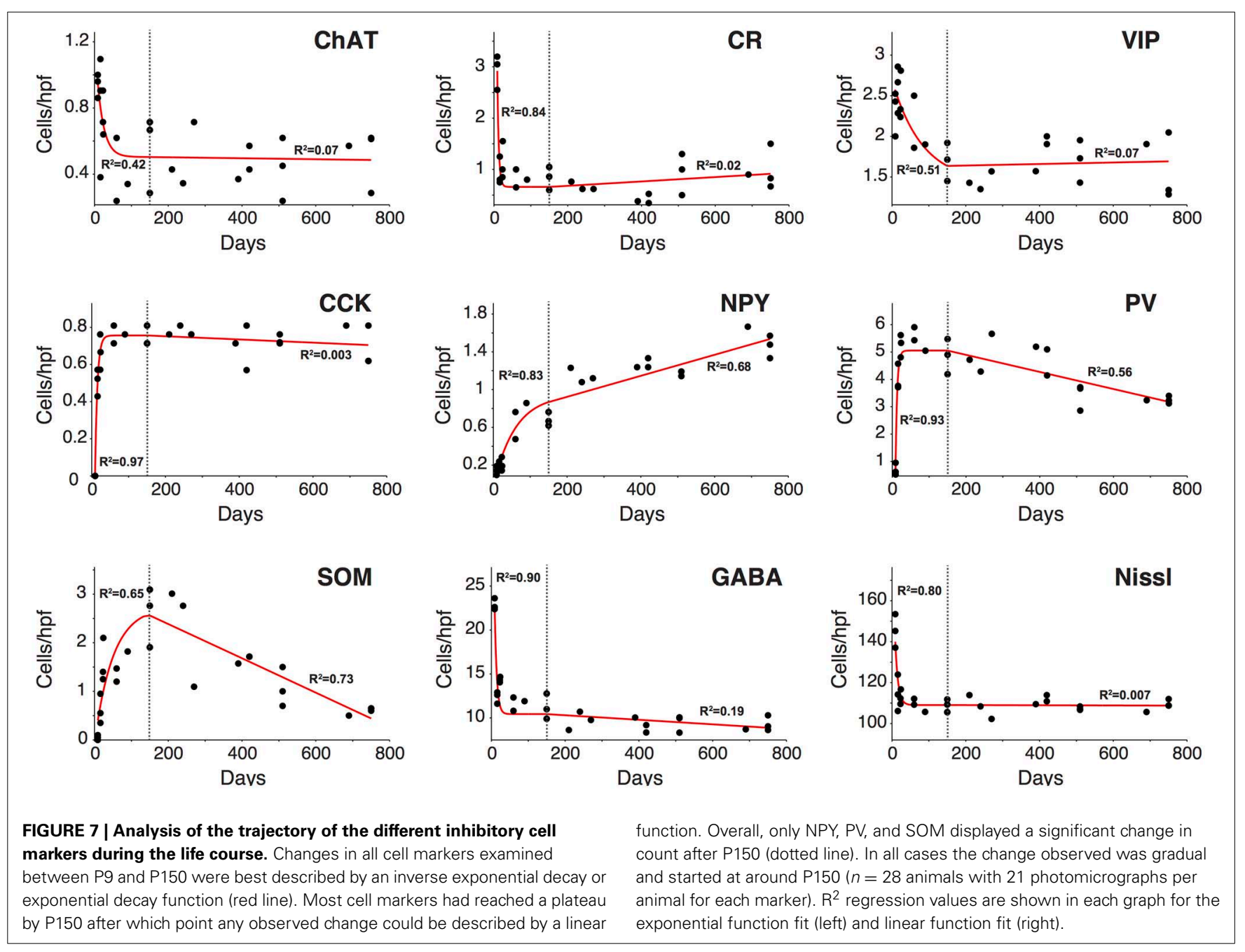

et al., 2013). However, this type of decline was not global, as $\mathrm{PV}$ and SOM-expressing neurons increased in a parabolic curve until late adulthood, when they, too, began to decline. In contrast, CR, VIP, and CCK-expressing cells maintained relatively stable expression across adulthood, with the above-mentioned early decrease in CR, VIP, and ChAT, and concomitant increase in NPY and CCK. Taken together, these trends suggest an orderly, programmed population trajectory that may be easily modeled through exponential decay curves followed by linear functions.

One of the most interesting aspects of our findings comes from the paucity of NPY, CCK, SOM, and PV expression early in the lifecourse (P20-120). To reiterate, our study was not able to determine whether this reflects evidence of low cell populations per se, but may rather reflect differing protein elaboration. While the latter possibility has not been fully explored, previous work in rodents, monkeys and humans has shown that these inhibitory interneuron markers have sparse expression in early developing cortex (Hof et al., 1999; Giacobini and Wray, 2008; Zecevic et al., 2011), but few have followed their trajectories over the entire lifecourse. What role could interneurons expressing these markers play in development? NPY is perhaps best known for its role in feeding, anxiety, and other homeostatic behaviors (Lin et al., 2004), but changing levels of its receptor expression have been implicated in age-related memory deficits and Alzheimer's disease (Minthon et al., 1996; Borbély et al., 2013). Furthermore, its tight coupling with cholinergic systems in the brain has pointed toward communication with other neuron subtypes in the cortex. CCK, too, is closely involved with a host of developmental processes in early life, including learning and sexual maturation (Giacobini and Wray, 2008). While all of these neuropeptide markers underlie a rich variety of cortical functions, our work has found them (with the exceptions of CCK) to be united by a common developmental trajectory, starting with low levels and plateauing around P120. This provides a large time window for functional maturation and opens exciting possibilities for exploring functional consequences of these fluctuating markers early in development.

In later life, this work has also provided important insights about the changing nature of GABAergic transmission. Unlike other markers, both PV and SOM showed a significant decrease beginning in mid-life between P120 and P350 and continuing to late adulthood at P700. It is unclear what special traits these markers may possess that somehow single them out for age-related 
population decline, but previous work has shed a great deal of light on their role in cognitive and sensory impairment. As early as 1993, both PV and SOM were known to decrease in sensory cortices (Miettinen et al., 1993), and since then, many studies have replicated these findings in other species and regions of the brain (Ouda et al., 2008; Caballero et al., 2013; Fish et al., 2013). For example, several groups have shown that SOM appears to be especially sensitive to both injury and aging than other interneuron subtypes (Lowenstein et al., 1992; Stanley et al., 2012). Furthermore, SOM's role in sensory processing and hippocampal excitation have implicated in several neurodegenerative conditions including Alzheimer's and Parkinson's disease (Patel, 1999; Viollet et al., 2008; Martel et al., 2012; Lin and Sibille, 2013). PV also seems to play a special role in age-related A1 functional decline (Ouda et al., 2008; Del Campo et al., 2012), however differs from SOM in one key aspect: its ability to be modified in response to activity in later life. Both de Villers-Sidani et al. (2010) and Kamal et al. (2013) have shown that PV-containing cells are sensitive to environments carrying high and low auditory information, respectively, and can up- or down-regulate their characteristic protein expression accordingly. This work raises the possibility that the expression of markers in cortical GABAergic neurons may be more sensitive to environmental information than previously believed. Thus, population fluctuations may better represent external stimuli than an ongoing neurodegenerative process.

However, PV and SOM were not the only cell types to show dramatic change in later life. Surprisingly and unexpectedly given previous findings from humans (Cha et al., 1996, 1997), NPY showed a significant increase between P20 and P350. We cannot fully explain this result, but offer a few tentative hypotheses: first, in humans, reduced NPY metabolism has been strongly correlated with Alzheimer's disease (Minthon et al., 1996; Borbély et al., 2013), suggesting that if NPY up-regulation is a consequence of normal aging, then its failure could lead to pathological results. Alternatively, NPY's involvement in cholinergic transmission (Nakhate et al., 2009) may be implicated, as the density of ChAT positive processes in our animals were greatly reduced in old age despite the stability of that cell population. NPY-expressing cells might thus have undertaken a compensatory mechanism for their ChAT counterparts, or more broadly for decay of PV and SOM expression. Our finding can support this interpretation that, despite widespread disappearance of the two most prominent GABAergic interneuron types, PV and SOM, numbers of cortical GABAergic cells remained essentially unchanged after P350.

In terms of global cortical changes over development and aging, our work in the present study has unearthed two major patterns. Early in life, all neuron subtypes were subject to exponential change, a pattern closely tied to the critical period window (de Villers-Sidani et al., 2007, 2008). However, in PV-, SOM-, and NPY-expressing cells change from P150 to P750 takes on a form more consistent with linear change. The remainder of our markers, CCK, ChAT, VIP, and CR, show relatively stable populations throughout adult life. At the most simple level, changes in interneuron marker expression may be grouped into four distinct categories: inverse exponential decay and plateau (CCK), inverse exponential decay and linear increase (NPY), exponential decay and plateau (ChAT, VIP, and CR), and inverse exponential decay followed by linear decrease (PV and SOM). Could these categories possibly be reflected by functional cortical characteristics? While answers remain elusive for the first three groups, there is good evidence to suggest that PV and SOM disappearance correlated temporally with the emergence of auditory cognitive impairments (Ouda et al., 2008; Burianova et al., 2009; de VillersSidani et al., 2010). Rather than pure cell death, these results could also reflect a large down-regulation of protein expression, as evidenced by resurgence of PV in Kamal et al. (2013). Whatever the cause, our work has provided a careful, population-based framework for monitoring different subtypes of GABAergic neurons and provided comparative population trends over the lifecourse.

Despite its successes, our study is, however, limited in several respects. First, our observations were limited to A1, which, although mirroring structural and functional aspects of many other cortical areas cannot accurately speak to changes in other brain regions. Secondly, our study was conducted in single strain of rats living in a relatively simple laboratory environment. Previous work has shown that both strain (Ouda et al., 2008) and environmental enrichment (de Villers-Sidani et al., 2010) can have a significant effect on interneuron populations. Additionally, our study did not systematically explore all possible interneuron markers, excluding, for example calbindin, NOS, doublecortin and 5-HT3. In the future, perhaps these interneuron subtypes may be fruitfully explored, and provide insights on the nature of GABAergic signaling and aging. It should also be mentioned that GABA immunoreactivity may provide only an estimate of GABAergic population as some inhibitory neurons might in some circumstance not be revealed by such antibodies. For example Von Engelhardt et al. (2007) found that only a subset of ChAT positive neurons co-express GAD67. In this study we have also noted that at P9 25\% of CR+ neurons were GABA negative. In future work with more advanced co-labeling techniques, perhaps these challenges may be resolved, providing the most accurate picture possible of how GABAergic interneurons change across the lifecourse.

In conclusion, this work has shown that different GABAergic interneuron subtypes display remarkable diversity across an animal's life, and coincide with many important functional benchmarks in development and aging. At first undergoing exponential increase, NPY, CCK-expressing cells plateau relatively early; while PV and SOM-expressing cells later show a marked decrease. ChAT, VIP, and CR-expressing cells exhibit an opposite pattern, undergoing a rapid decrease in just the first few days of life. These results shed light on the already complex debate surrounding inhibition and aging, and provide some insights on just how the cortex's profile of excitation and inhibition changes across the lifecourse. With respect to the reduced inhibition seen in the aged auditory system (Caspary et al., 2008; de Villers-Sidani et al., 2010), we believe that our characterization of PV and SOMexpressing cells' decline represents a fruitful avenue for future research. Perhaps understanding the delicate balance of inhibitory transmission in normal aging will provide clues to ongoing functional processes or even neurodegenerative processes such as Alzheimer's disease. Whatever the outcome, we believe that this 
characterization of cortical GABAergic interneurons has provided intriguing questions for future research, and helped further enrich our image of the brain from birth to death.

\section{AUTHOR CONTRIBUTIONS}

Lydia Ouellet and Etienne de Villers-Sidani designed the experiments. Lydia Ouellet performed the experiments. Etienne de Villers-Sidani and Lydia Ouellet performed analysis. Lydia Ouellet and Etienne de Villers-Sidani wrote the paper.

\section{ACKNOWLEDGMENTS}

The authors would like to thank Constance Holman for her help in writing process as well as Étienne Joly-Lopez for his help with statistical analysis. This work was supported by Canadian Institutes for Health Research (Open Operating Grant Program and Clinician-Scientist Award, the Fonds de Recherche en Santé du Québec (Bourse d'établissement de Jeune Chercheur) and the Canadian Foundation for Innovation (CFI infrastructure grant 28121).

\section{REFERENCES}

Akbarian, S., Kim, J. J., Potkin, S. G., Hagman, J. O., Tafazzoli, A., Bunney, W. E., et al. (1995). Gene expression for glutamic acid decarboxylase is reduced without loss of neurons in prefrontal cortex of schizophrenics. Arch. Gen. Psychiatry 52, 258-266. doi: 10.1001/archpsyc.1995.03950160008002

Anderson, S. A., Kaznowski, C. E., Horn, C., Rubenstein, J. L., and McConnell, S. K. (2002). Distinct origins of neocortical projection neurons and interneurons in vivo. Cereb. Cortex 12, 702-709. doi: 10.1093/cercor/12.7.702

Anomal, R., de Villers-Sidani, E., Merzenich, M. M., and Panizzutti, R. (2013). Manipulation of BDNF signaling modifies the experience-dependent plasticity induced by pure tone exposure during the critical period in the primary auditory cortex. PLOS ONE 8:e64208. doi: 10.1371/journal.pone.00 64208

Ascoli, G. A., Alonso-Nanclares, L., Anderson, S. A., Barrionuevo, G., BenavidesPiccione, R., Burkhalter, A., et al. (2008). Petilla terminology: nomenclature of features of GABAergic interneurons of the cerebral cortex. Nat. Rev. Neurosci. 9, 557-568. doi: 10.1038/nrn2402

Bartolini, G., Ciceri, G., and Marin, O. (2013). Integration of GABAergic interneurons into cortical cell assemblies: lessons from embryos and adults. Neuron 79, 849-864. doi: 10.1016/j.neuron.2013.08.014

Bartos, M., Vida, I., and Jonas, P. (2007). Synaptic mechanisms of synchronized gamma oscillations in inhibitory interneurons networks. Nat. Rev. Neurosci. 8, 45-56. doi: 10.1038/nrn2044

Bao, S., Chang, E. F., Davis, J. D., Gobeske, K. T., and Merzenich, M. M. (2003). Progressive degradation and subsequent refinement of acoustic representations in the adult auditory cortex. J. Neurosci. 23, 10765-10775.

Beaulieu, C. (1993). Numerical data on neocortical neurons in adult rat, with special reference to the GABA population. Brain Res. 609, 284-292. doi: 10.1016/0006-8993(93)90884-P

Benes, F. M., Vincent, S. L., Marie, A., and Khan, Y. (1996). Up-regulation of $\mathrm{GABA}_{A}$ receptor binding on neurons of the prefrontal cortex in schizophrenic subjects. Neuroscience 75, 1021-1031. doi: 10.1016/0306-4522(96)00328-4

Beierlein, M., Gibson, J. R., and Connors, B. W. (2000). A network of electrically coupled interneurons drives synchronized inhibition in neocortex. Nat. Neurosci. 3, 904-910. doi: 10.1038/78809

Borbély, E., Scheich, B., and Helyes, Z. (2013). Neuropeptides in learning and memory. Neuropeptides 47, 439-450. doi: 10.1016/j.npep.2013.10.012

$\mathrm{Bu}$, J., Sathyendra, V., Nagykery, N., and Geula, C. (2003). Age-related changes in calbindin-D28k, calretinin, and parvalbumin-immunoreactive neurons in the human cerebral cortex. Exp. Neurol. 182, 220-231. doi: 10.1016/S00144886(03)00094-3

Burianova, J., Ouda, L., Profant, O., and Syka, J. (2009). Age-related changes in GAD levels in the central auditory system of the rat. Exp. Gerontol. 44, 161-169. doi: 10.1016/j.exger.2008.09.012
Butt, S. J., Fuccillo, M., Nery, S., Noctors, S., Kriegstein, A., Corbin, J. G. et al. (2005). The temporal and spatial origins of cortical interneurons predict their physiological subtype. Neurons 48, 591-604. doi: 10.1016/j.neuron.2005.09.034

Caballero, A., Diah, K. C., and Tseng, K. Y. (2013). Region-specific upregulation of parvalbumin-, but not calretinin-positive cells in the ventral hippocampus during adolescence. Hippocampus 23, 1331-1336. doi: 10.1002/hipo.22172

Cardin, J. A., Carlén, M., Meletis, K., Knoblich, U., Zhang, F., Deisseroth, K., et al. (2009). Driving fast-spiking cells induce gamma rhythm and controls sensory responses. Nature 459, 663-667. doi: 10.1038/nature08002

Caspary, D. M., Ling, L., Turner, J. G., and Hughes, L. F. (2008). Inhibitory neurotransmission, plasticity and aging in the mammalian central auditory system. J. Exp. Biol. 211, 1781-1791. doi: 10.1242/jeb.013581

Cha, C. I., Lee, E. Y., Park, K. H., and Baik, S. H. (1997). Age-related changes of VIP, NPY and somatostatin-immunoreactive neurons in the cerebral cortex of aged rats. Brain Res. 753, 235-244. doi: 10.1016/S0006-8993(97)00009-7

Cha, C. I., Lee, Y. I., and Baik, S. H. (1996). Age-related change of neuropeptide Yimmunoreactive neurons in the cerebral cortex of aged rats. Neurosci. Lett. 214, 37-40. doi: 10.1016/0304-3940(96)12876-7

Chang, E. F., Bao, S., Imaizumi, K., Schreiner, C. E., and Merzenich, M. M. (2005). Development of spectral and temporal response selectivity in the auditory cortex. Proc. Natl. Acad. Sci. U.S.A. 102, 16460-16465. doi: 10.1073/pnas.0508239102

Cossart, R., Dinocourt, C., Hirsch, J. C., Merchan-Perez, A., De Felipe, J., Ben-Ari, Y., et al. (2001). Dendritic but not somatic GABAergic inhibition is decreased in experimental epilepsy. Nat. Neurosci. 4, 52-62. doi: 10.1038/82900

Dani, V. S., Chang, Q., Maffe, A., Turrigiano, G. G., Jaenisch, R., and Nelson, S. B. (2005). Reduced cortical activity due to a shift in the balance between excitation and inhibition in a mouse model of Rett Syndrome. Proc. Natl. Acad. Sci. U.S.A. 102, 12560-12565. doi: 10.1073/pnas.0506071102

DeFelipe, J. (1993). Neocortical neuronal diversity: chemical heterogeneity revealed by colocalization studies of classic neurotransmitters, neuropeptides, calcium binding proteins, and cell surface molecules. Cereb. Cortex 3, 273-289. doi: 10.1093/cercor/3.4.273

DeFelipe, J., Lopez-Cruz, P. L., Benavides-Piccione, R., Bielza, C., Larranaga, P., Anderson, S. et al. (2013). New insights into the classification and nomenclature of cortical GABAergic interneurons. Nat. Rev. Neurosci. 14, 202-216. doi: $10.1038 / \mathrm{nrn} 3444$

Del Campo, C. H. N., Measor, K. R., and Razak, K. A. (2012). Parvalbuminimmunoreactivity in the auditory cortex of a mouse model of presbycusis. Hear. Res. 294, 31-39. doi: 10.1016/j.heares.2012.08.017

Del Rio, M. R., and DeFelipe, J. (1997). Colocalization of parvalbumin and calbindin D-28k in neurons including chandelier cells of the human temporal cortex. J. Chem. Neuroanat. 12, 165-173. doi: 10.1016/S0891-0618(96)00191-3

de Villers-Sidani, E., Alzghoul, L., Zhou, X., Simpson, K. L., Lin, R. C., and Merzenich, M. M. (2010). Recovery of functional and structural age-related changes in the rat primary auditory cortex with operant training. Proc. Natl. Acad. Sci. U.S.A. 107, 13900-13905. doi: 10.1073/pnas.1007885107

de Villers-Sidani, E., Chang, E. F., Bao, S. B., and Merzenich, M. M. (2007). Critical period window for spectral tuning defined in the primary auditory cortex (A1) in the rat. J. Neurosci. 27, 180-189. doi: 10.1523/JNEUROSCI.3227-06.2007

de Villers-Sidani, E., and Merzenich, M. M. (2011). Lifelong plasticity in the rat auditory cortex: basic mechanisms and role of sensory experience. Prog. Brain Res. 191, 119-131. doi: 10.1016/B978-0-444-53752-2. 00009-6

de Villers-Sidani, E., Simpson, K. L., Lu, Y. F., Lin, R. C. S., and Merzenich, M. M. (2008). Manipulating critical period closure across different sectors of the primary auditory cortex. Nat. Neurosci. 11, 957-965. doi: 10.1038/nn.2144

Dreifuss, J. J., Kelly, J. S., and Krnjevic, K. (1969). Cortical inhibition and gammaaminobutyric acid. Exp. Brain Res. 9, 137-154. doi: 10.1007/BF00238327

Fagiolini, M., and Hensch, T. K. (2000). Inhibitory threshold for critical-period activation in primary visual cortex. Nature 404, 183-186. doi: 10.1038/ 35004582

Fish, K. N., Hoftman, G. D., Sheikh, W., Kitchens, M., and Lewis, D. A. (2013). Parvalbumin-containing chandelier and basket cell boutons have distinctive modes of maturation in monkey prefrontal cortex. J. Neurosci. 33, 8352-8358. doi: 10.1523/JNEUROSCI.0306-13.2013

Fitzpatrick, D., Lund, J. S., Schmechel, D. E., and Towles, A. C. (1987). Distribution of GABAergic neurons and axon terminals in the macaque striate cortex. J. Comp. Neurol. 264, 73-91. doi: 10.1002/cne.902640107 
Fries, P., Schröder, J. H., Roelfsema, P. R., Singer, W., and Engel, A. K. (2002). Oscillatory neuronal synchronization in primary visual cortex as a correlate of stimulus selection. J. Neurosci. 22, 3739-3754.

Froemke, R. C., Merzenich, M. M., and Schreiner, C. E. (2007). A synaptic memory trace for cortical receptive field plasticity. Nature 450, 425-429. doi: 10.1038/nature06289

Fox, K., and Wong, O. L. (2005). A comparison of experience-dependant plasticity in the visual and somatosensory system. Neuron 48, 465-477. doi: 10.1016/j.neuron.2005.10.013

Games, K. D., and Winer, J. A. (1988). Layer V in rat auditory cortex: projections to the inferior colliculus and contralateral cortex. Hear. Res. 34, 1-25. doi: 10.1016/0378-5955(88)90047-0

Gelman, D. M., and Marin, O. (2010). Generation of interneuron diversity in the mouse cerebral cortex. Eur. J. Neurosci. 31, 2136-2141. doi: 10.1111/j.14609568.2010.07267.x

Giacobini, P., and Wray, S. (2008). Prenatal expression of cholecystokinin (CCK) in the central nervous system (CNS) of mouse. Neurosci. Lett. 438, 96-101. doi: 10.1016/j.neulet.2008.04.042

Gonchar, Y., and Burkhalter, A. (1997). Three distinct families of GABAergic neurons in rat visual cortex. Cereb. Cortex 7, 347-358. doi: 10.1093/cercor/7.4.347

Gonchar, Y., Wang, Q., and Burkhalter, A. (2008). Multiple distinct subtypes of GABAergic neurons in mouse visual cortex identified by triple immunostaining. Front. Neuroanat. 1:3. doi: 10.3389/neuro.05.003.2007

Hazra, A., Gu, F., Aulakh, A., Berridge, C., Eriksen, J. L., and Žiburkus, J. (2013). Inhibitory neuron and hippocampal circuit dysfunction in an aged mouse model of alzheimer's disease. PLOS ONE 8:e64318. doi: 10.1371/journal.pone. 0064318

Hendry, S. H., Schwark, H. D., Jones, E. G., and Yan, J. (1987). Numbers and proportions of GABA-immunoreactive neurons in different areas of monkey cerebral cortex. J. Neurosci. 7, 1503-1519.

Hensch, T. K. (2004). Critical period regulation. Annu. Rev. Neurosci. 27, 549-579. doi: 10.1146/annurev.neuro.27.070203.144327

Hensch, T. K. (2005). Critical period plasticity in local cortical circuits. Nat. Rev. Neurosci. 6, 877-888. doi: 10.1038/nrn1787

Hensch, T. K., Fagiolini, M., Mataga, N., Stryker, M. P., Baekkeskov, S., and Kash, S. F. (1998). Local GABA circuit control of experience-dependent plasticity in developing visual cortex. Science 282, 1504-1508. doi: 10.1126/science.282.5393.1504

Hof, P. R., Glezer, I. I., Condé, F., Flagg, R. A., Rubin, M. B., Nimchinsky, E. A. et al. (1999). Cellular distribution of the calcium-binding proteins parvalbumin, calbindin, and calretinin in the neocortex of mammals: phylogenetic and developmental patterns. J. Chem. Neuroanat. 16, 77-116. doi: 10.1016/S08910618(98)00065-9

Kamal, B., Holman, C., and de Villers-Sidani, E. (2013). Shaping the aging brain: role of auditory input patterns in the emergence of auditory cortical impairments. Front. Syst. Neurosci. 7:52. doi: 10.3389/fnsys.2013.00052

Kowiański, P., Moryś, J. M., Wójcik, S., Dziewiatkowski, J., Luczyñska, A., Spodnik, E., et al. (2004). Neuropeptide-containing neurons in the endopiriform region of the rat: morphology and colocalization with calciumbinding proteins and nitric oxide synthase. Brain Res. 996, 97-110. doi: 10.1016/j.brainres.2003.10.020

Kubota, Y., Hattori, R., and Yui, Y. (1994). Three distinct subpopulations of GABAergic neurons in rat frontal agranular cortex. Brain Res. 649, 159-173. doi: 10.1016/0006-8993(94)91060-X

Lehmann, K., Steinecke, A., and Bolz, J. (2012). GABA through the ages: regulation of cortical function and plasticity by inhibitory interneurons. Neural Plasticity 2012:892784. doi: 10.1155/2012/892784

Letinic, K., Zoncu, R., and Rakic, P. (2002). Origin of GABAergic neurons in the human neocortex. Nature 417, 645-649. doi: 10.1038/nature00779

Letzkus, J. J., Wolff, S. B., Meyer, E. M., Tovote, P., Courtin, J., Herry, C. et al. (2011). A disinhibitory microcircuit for associative fear learning in the auditory cortex. Nature 480, 331-335. doi: 10.1038/nature10674

Levitt, P. (2005). Disruption of interneuron development. Epilepsia 46, 22-28. doi: 10.1111/j.1528-1167.2005.00305.x

Levitt, P., Eagleson, K. L., and Powell, E. M. (2004). Regulation of neocortical interneuron development and the implications for neurodevelopmental disorders. Trends Neurosci. 27, 400-406. doi: 10.1016/j.tins.2004. 05.008
Lewis, D. A. (2000). GABAergic local circuit neurons and prefrontal cortex dysfunction in schizophrenia. Brain Res. Rev. 31, 270-276. doi: 10.1016/S01650173(99)00042-9

Lewis, D. A., Hashimoto, T., and Volk, D. W. (2005). Cortical inhibitory neurons and schizophrenia. Nat. Rev. Neurosci. 6, 312-324 doi: 10.1038/nrn1648

Lin, L.-C., and Sibille, E. (2013). Reduced brain somatostatin in mood disorders: a common pathophysiological substrate and drug target? Front. Pharmacol. 4, 1-12. doi: 10.3389/fphar.2013.00110

Lin, S., Boey, D., and Herzog, H. (2004). NPY and Y receptors: lessons from transgenic and knockout models. Neuropeptides 38, 189-200. doi: 10.1016/j.npep.2004.05.005

Linden, J. F. (2012). Consequences of chronic reduction of cortical inhibition. PNAS 109, 13473-13474. doi: 10.1073/pnas.1210409109

Lowenstein, D. H., Thomas, M. J., Smith, D. H., and McIntosh, T. K. (1992). Selective vulnerability of dentate hilar neurons following traumatic brain injury: a potential mechanistic link between head trauma and disorders of the hippocampus. J. Neurosci. 12, 4846-4853.

Maffei, A., Nataraj, K., Nelson, S. B., and Turrigiano, G. G. (2006). Potentiation of cortical inhibition by visual deprivation. Nature 443, 81-84. doi: 10.1038 /nature05079

Marin, O. (2012). Interneuron dysfunction in psychiatric disorders. Nat. Rev. Neurosci. 13, 107-120. doi: 10.1038/nrn3155

Markram, H., Toledo-Rodriguez, M., Wang, Y., Gupta, A., Silberberg, G., and Wu, C. (2004). Interneurons of the neocortical inhibitory system. Nat. Rev. Neurosci. 5, 793-807. doi: 10.1038/nrn1519

Martel, G., Dutar, P., Epelbaum, J., and Viollet, C. (2012). Somatostatinergic systems: an update on brain functions in normal and pathological aging. Front. Endocrinol. 3:154. doi: 10.3389/fendo.2012.00154

Martinez, L. M., Alonso, J. M., Reid, R. C., and Hirsch, J. A. (2002). Laminar processing of stimulus orientation in cat visual cortex. J. Physiol. 540, 321-333. doi: 10.1113/jphysiol.2001.012776

McBain, C. J., and Fisahn, A. (2001). Interneurons unbound. Nat. Rev. Neurosci. 2, 11-23. doi: 10.1038/35049047

Miettinen, R., Sirvio, J., Riekkinen, P., Laakso, M. P., Riekkinen, M., and Riekkinen, P. (1993). Neocortical, hippocampal and septalparvalbumin- and somatostatincontaining neurons in young and aged rats: correlation with passive avoidance and water maze performance. Neuroscience 53, 367-378. doi: 10.1016/03064522(93)90201-P

Minthon, L., Edvinsson, L., and Gustafson, L. (1996). Correlation between clinical characteristics and cerebrospinal fluid neuropeptide Y levels in dementia of the Alzheimer type and frontotemporaldementia. Alzheimer Dis. Assoc. Disord. 10, 197-203.

Miyoshi, G., Butt, S. J. B., Takebayashi, H., and Fishell, G. (2007). Physiologically distinct temporal cohorts of cortical interneurons arise from telencephalic Olig2-expressing precursors. J. Neurosci. 27, 7786-7798. doi: 10.1523/JNEUROSCI.1807-07.2007

Molnár, Z., Métin, C., Stoykova, A., Tarabykin, V., Price, D. J., Francis, F., et al. (2006). Comparative aspects of cerebral cortial development. Eur. J. Neurosci. 23, 921-934. doi: 10.1111/j.1460-9568.2006.04611.x

Morino, P., Herrara-Marschitz, M., Castel., M. N., Ungerstedt, U., Varro, A., Dockray, G. et al. (1994). Cholecystokinin in cortico-striatal neurons in the rat: immunohistochemical studies at the light and electron microscopical level. Eur. J. Neurosci. 6, 681-692. doi: 10.1111/j.1460-9568.1994.tb00980.x

Nakhate, K. T., Dandekar, M. P., Kokare, D. M., and Subhedar, N. K. (2009). Involvement of neuropeptide Y Y(1) receptors in the acute, chronic and withdrawal effects of nicotine on feeding and body weight in rats. Eur J. Pharmacol. 609, 78-87. doi: 10.1016/j.ejphar.2009.03.008

Ouda, L., Druga, R., and Syka, J. (2008). Changes in parvalbumin immunoreactivity with aging in the central auditory system of the rat. Exp. Gerontol. 43, 782-789. doi: 10.1016/j.exger.2008.04.001

Patel, Y. C. (1999). Somatostatin and its receptor family. Front. Neuroendocrinol. 20, 157-198. doi: 10.1006/frne.1999.0183

Pinto, J., Hornby, K., Jones, D., and Murphy, K. (2010). Developmental changes in GABAergic mechanisms in human visual cortex across the lifespan. Front. Cell. Neurosci. 4:16. doi: 10.3389/fncel.2010.00016

Pugliese, M., Carrasco, J. L., Geloso, M. C., Mascort, J., Michetti, F., and Mahy, N. (2004). Gamma-aminobutyric acidergic interneuron vulnerability to aging in canine prefrontal cortex. J. Neurosci. Res. 77, 913-920. doi: 10.1002/jnr.20223 
Razak, K. A., and Fuzessery, Z. M. (2009). GABA shapes selectivity for the rate and direction of frequency-modulated sweeps in the auditory cortex. J. Neurophysiol. 102, 1366-1378. doi: 10.1152/jn.00334.2009

Rubenstein, J. H., and Merzenich, M. M. (2003). Model of autism: increase ratio of excitation/inhibition in key neural systems. Genes Brain Behav. 2, 255-267. doi: 10.1034/j.1601-183X.2003.00037.x

Rudy, B., Fishell, G., Lee, S., and Hjerling-Leffler, J. (2011). Three groups of interneurons account for nearly $100 \%$ of neocortical GABAergic neurons. Dev. Neurobiol. 71, 45-61. doi: 10.1002/dneu.20853

Sanacora, G., Mason, G. F., and Krystal, J. H. (2000). Impairment of GABAergic transmission in depression: new insights from neuroimaging studies. Crit. Rev. Neurobiol. 14, 23-45. doi: 10.1615/CritRevNeurobiol.v14.i1.20

Schettini, G. (1991). Brain somatostatin: receptor-coupled transducing mechanisms and role in cognitive functions. Pharmacol. Res. 23, 203-215. doi: 10.1016/S1043-6618(05)80080-5

Schulze, H., and Langner, G. (1999). Auditory cortical responses to amplitude modulations with spectra above frequency receptive fields: evidence for wide spectral integration. J. Comp. Physiol. 185, 493-508. doi: 10.1007/s003590050410

Sohal, V. S., Zhang, F., Yizhar, O., and Deisseroth, K. (2009). Parvalbumin neurons and gamma rhythms enhance cortical circuit performance. Nature 459, 698-702. doi: 10.1038/nature07991

Somogyi, P., Freund, T. F., Wu, J. Y., and Smith, A. D. (1983). The section-Golgi impregnation procedure. Immunocytochemical demonstration of glutamate decarboxylase in Golgi-impregnated neurons and in their afferent synaptic boutons in the visual cortex of the cat. Neuroscience 9, 475-490. doi: 10.1016/0306-4522(83)90167-7

Somogyi, P., and Klausberger, P. (2005). Defined types of interneurone structure space and spike timing in the hippocampus. J. Physiol. 562, 9-26. doi: 10.1113/jphysiol.2004.078915

Stanley, E. M., Fadel, J. R., and Mott, D. D. (2012). Interneuron loss reduces dendritic inhibition and GABA release in hippocampus of aged rats. Neurobiol. Aging 33, e1-431.13. doi: 10.1016/j.neurobiolaging.2010.12.014

Tallon-Baudry, C., Bertrand, O., Peronnet, F., and Pernier, J. (1998). Induced $\gamma$ band activity during the delay of a visual short term memory task in humans. J. Neurosci. 18, 4244-4254.

Tong, Z., Han, C., Luo, W., Li, H., Luo, H., Qiang, M., et al. (2013). Agingassociated excess formaldehyde leads to spatial memory deficits. Sci. Rep. 3, 1807. doi: 10.1038/srep01807

Valcanis, H., and Tan, S. S. (2003). Layer specification of transplanted interneurons in developing mouse neocortex. J. Neurosci. 23, 5113-5122.

Vecsei, L., and Widerlov, E. (1990). Preclinical and clinical studies with cysteamine and pantethine related to the central nervous system. Prog. Neuropsychopharmacol. Biol. Psychiatry 14, 835-862.

Vela, J., Gutierrez, A., Vitorica, V., and Ruano, D. (2003). Rat hippocampal GABAergic molecular markers are differentially affected by ageing. J. Neurochem. 85, 368-377. doi: 10.1046/j.1471-4159.2003.01681.x

Verret, L., Mann, E. O., Hang, G. B., Barth, A. M. I., Cobos, I., Ho, K., et al. (2012). Inhibitory interneuron deficit links altered network activity and cognitive dysfunction in alzheimer model. Cell 149, 708-721. doi: 10.1016/j.cell.2012.02.046
Viollet, C., Lepousez, G., Loudes, C., Videau, C., Simon, A., and Epelbaum, J. (2008). Somatostatinergic systems in brain: networks and functions. Mol. Cell. Endocrinol. 286, 75-87. doi: 10.1016/j.mce.2007.09.007

Von Engelhardt, J., Eliava, M., Meyer, A. H., Rozov, A., and Monyer, H. (2007). Functional characterization of intrinsic cholinergic interneurons in the cortex. J. Neurosci. 27, 5633-5642. doi: 10.1523/JNEUROSCI.4647-06.2007

Wehr, M., and Zador, A. M. (2003). Balanced inhibition underlies tuning and sharpens spike timing in auditory cortex. Nature 426, 442-446. doi: 10.1038/nature02116

Wonders, C. P., and Anderson, S. A. (2006). The origin and specification of cortical interneurons. Nat. Rev. Neurosci. 7, 687-696. doi: 10.1038/nrn1954

Wu, G. K., Arbuckle, R., Liu, B-H., Tao, H. W., and Zhang, L. I. (2008). Lateral sharpening of cortical frequency tuning by approximately balanced inhibition. Neuron 58, 132-143. doi: 10.1016/j.neuron.2008.01.035

Xu, Q., De La Cruz, E., Rubenstein, J. L., and Anderson, S. A. (2004). Origins of cortical interneuron subtypes. J. Neurosci. 24, 2612-2622. doi: 10.1523/JNEUROSCI.5667-03.2004

Xu, X., Roby, K. D., and Callaway, E. M. (2006). Mouse cortical inhibitory neuron type that coexpresses somatostatin and calretinin. J. Comp. Neurol. 499, 144-160. doi: 10.1002/cne.21101

Xu, X., Roby, K. D., and Callaway, E. M. (2010). Immunochemical characterization of inhibitory mouse cortical neurons: three chemically distinct classes of inhibitory cells. J. Comp. Neurol. 518, 389-404. doi: 10.1002/cne.22229

Yan, Y.-H., Van Brederode, J. F. M., and Hendrickson, A. E. (1995). Transientcolocalization of calretinin, parvalbumin, and calbindin-D28 in developing visual cortex of monkey. J. Neurocytol. 24, 825-837. doi: 10.1007/BF01179982

Yizhar, O., Fenno, L. E., Prigge, M., Schneider, F., Davidson, T. J., O’Shea, D. J., et al. (2011). Neocortical excitation/inhibition balance in information processing and social dysfunction. Nature 477, 171-178. doi: 10.1038/nature10360

Yuste, R. (2005). Origin and classification of neocortical interneurons. Neuron 48, 524-527. doi: 10.1016/j.neuron.2005.11.012

Zecevic, N., Hu, F., and Jakovcevski, I. (2011). Interneurons in the developing human neocortex. Dev. Neurobiol. 71, 18-33. doi: 10.1002/dneu.20812

Conflict of Interest Statement: The authors declare that the research was conducted in the absence of any commercial or financial relationships that could be construed as a potential conflict of interest.

Received: 04 March 2014; accepted: 13 May 2014; published online: 02 June 2014. Citation: Ouellet L and de Villers-Sidani E (2014) Trajectory of the main GABAergic interneuron populations from early development to old age in the rat primary auditory cortex. Front. Neuroanat. 8:40. doi: 10.3389/fnana.2014.00040

This article was submitted to the journal Frontiers in Neuroanatomy.

Copyright (c) 2014 Ouellet and de Villers-Sidani. This is an open-access article distributed under the terms of the Creative Commons Attribution License (CC BY). The use, distribution or reproduction in other forums is permitted, provided the original author(s) or licensor are credited and that the original publication in this journal is cited, in accordance with accepted academic practice. No use, distribution or reproduction is permitted which does not comply with these terms. 